CUERPO Y MODA 

Daimon. Revista Internacional de Filosofía, Suplemento 5 (2016), 499-506

ISSN: 1130-0507 (papel) y 1989-4651 (electrónico)

http://dx.doi.org/10.6018/daimon/269531

\title{
Cuerpos de la historia cultural del XX: la garçonne y la pin-up
}

\section{Bodies of cultural history XX: the garçonne and pin-up}

\author{
MERCEDES EXPÓSITO GARCÍA*
}

\begin{abstract}
Resumen: Al igual que en cualquier otra época histórica, los relatos políticos, artísticos y culturales del siglo XX mostraron su capacidad para reorganizar los cuerpos a su manera. Tanto la vestimenta como la morfología corporal se adaptaron a los ideales de una mujer nueva en una nueva civilización que abandonó el corsé y rompió con los códigos del orden burgués y victoriano anterior para liberar un tercer sexo que superase la sexuación del mundo, basada en los dos sexos que se daban por establecidos. Es una garçonne que desatará una posterior reacción conservadora con la vuelta de un estereotipo: la pin up.

Palabras clave: Cuerpo, moda, garçonne, pin up.
\end{abstract}

\begin{abstract}
As any other historical epoch, the political, artistic and cultural statements of the 20th century had aptitude to reorganize the bodies to his way. Both the gown and the corporal morphology adapted to the ideal ones of a new woman in a new civilization that left the corset and it was breaking with the codes of the previous bourgeois and Victorian order to liberate the third sex that was overcoming the sexuación of the world, based on both established sexes. It is a garçonne to unleash a conservative subsequent reaction with the return of a stereotype: the pin up. Keywords: Body, fashion, garçonne, pin up.
\end{abstract}

Los comienzos del siglo XX, esos años que con frecuencia se nombran de manera significativa como belle epoque y años locos, estuvieron marcados por las apasionadas confrontaciones ideológicas de un tiempo de vanguardias que se muestran en su arte, en la política y en los relatos literarios y cinematográficos del cine mudo. Y en ese mundo efervescente, en el que los tiempos urbanos se vuelven cada vez más acelerados, se alza el vasto movimiento, disruptivo y anti-reaccionario, que estaba poniendo sus esperanzas en la construcción de una nueva civilización ${ }^{1}$ para las mujeres. Es un cambio de mentalidad que constituye el movimiento social de las mujeres modernas, mujeres que pugnan por su derecho a la libertad, a entrar en la universidad y en la esfera pública, mujeres que rompen

Fecha de recepción: 10/06/2016. Fecha de aceptación: 06/09/2016.

* E-mail: mercedessmer@gmail.com. Investigadora Independiente en Historia Cultural (historia de la diferencia sexual, filosofía feminista). Cfr. Expósito, M. (2016), De la Garçonne a la Pin Up. Mujeres y hombres en el siglo $X X$, Madrid: Cátedra.

1 Cfr Expósito, M. (2016) «La Nueva Civilización», en: M. Expósito: De la Garçonne a la Pin Up. Mujeres y hombres en el siglo XX. Madrid: Cátedra, pp. 71-92. 
con la generación anterior y buscan un estilo de vida independiente, jóvenes urbanas que tratan de realizarse en una profesión y que se dan cuenta de que la independencia pasa por la libertad del cuerpo y sus movimientos, por la ruptura, por tanto, con un orden de representaciones conservador que trataba de relegarlas al espacio de la casa y la domesticidad. Ahora las mujeres se apropian de espacios de todo tipo, de los mismos de los que hasta ese momento estaban excluidas formal o informalmente.

Por ejemplo, al reclamar para sí la novedosa práctica del deporte, un acontecimiento que irrumpe a comienzos el $\mathrm{XX}$, estas mujeres favorables a la nueva civilización tomaron conciencia de una dimensión activa de la feminidad, de un cuerpo móvil que muchos pensaban que se acercaba demasiado a la masculinidad y ponía en jaque la diferencia de sexos. Algunas, como la diseñadora estadounidense Amelia Bloomer, provocaron un fuerte escándalo con sus diseños: los "bloomers", unos bombachos diseñados para que las mujeres pedaleasen más cómodamente en sus bicicletas, fueron unas prendas que se convirtieron en peligrosas en un momento histórico en que una mujer en bicicleta era síntoma de rebeldía, abandono de la feminidad establecida e incluso inmoralidad.

Pero es en los diseños de una "garçonne" como Coco Chanel$^{2}$, una joven provinciana que llega a Paris desde una zona rural del norte de Francia para convertirse en modista, un sueño que compartía con los miles y miles de francesas que hacían las maletas desde todos los puntos del país, donde aparece con más fuerza el dinamismo de las nuevas propuestas. Con unos diseños en los que se abandona el corsé, una prenda que pasará a ser el símbolo de la anterior sumisión y opresión de las mujeres, quiere dejarse atrás la constricción del cuerpo por el vestido para construir la mujer nueva. En un período de crecimiento de las metrópolis, abandono de zonas rurales e industrialización creciente, Chanel recoge el estilo vestimentario cómodo, sobrio y sencillo, de las obreras y las trabajadoras de las fábricas (la petite robe noire), rediseñando el cuerpo femenino como una figura simplificada y rectilínea en uniforme de trabajo, una apariencia que acerca las fisionomías de los dos sexos y apenas marca diferencias con la masculina. La modista Coco Chanel sabe recoger el nuevo espíritu andrógino del tiempo en una figura móvil apta para la agitación de las nuevas metrópolis. La silueta que Chanel tiene en mente para sus diseños es un cuerpo que borra atributos femeninos como el pecho y las caderas, símbolos de un eterno femenino encarnado en una feminidad burguesa y victoriana que las mujeres nuevas y modernas querían dejar atrás. La "señora figurín" de los tiempos pasados, con sombrilla, vestidos y sombreros recargados de cintas y flores artificiales, deja paso a la nueva delgadez estilizada y parca que Chanel pone de moda. Ahora hasta las mujeres de la alta burguesía se cortan el pelo "a lo garçonne", en cortes masculinizados, y quieren ser maigres como Coco ${ }^{3}$. Aún más, una garçonne como Madeleine Pelletier, que al igual que algunas estudiantes y escritoras de finales del XIX adopta para sí el riguroso traje masculino y la corbata, habría separado masculinidad y feminidad de sus incardinaciones en los cuerpos físicos, revelando lo que tienen de construcción social y desarrollando una fuerte conciencia de las consecuencias psicológicas de vestirse de hombre, efectos en la propiocepción como la confianza en sí y la sensación de poder y fuerza física. Llamar la atención sobre la apariencia bella suponía, por el contrario, rebajarse

2 Cfr «Coco Chanel se corta el pelo» en: M. Expósito: De la Garçonne a la Pin Up. Mujeres y hombres en el siglo XX. Madrid: Cátedra, pp. 133-160.

3 Delgadas como Coco. 
a la posición de sumisión y pasividad del objeto sexual, así que esta nueva propuesta de subjetividad androgina y activa quedaría exenta del estigma de la feminidad. María Verona, editora de "Le Droit des femmes", expresó de un modo muy claro estas tendencias cuando afirmaba: "llevamos el pelo corto, vestidos que no nos constriñen y queremos tener una profesión con vistas a ser independientes"

Pero las formas de la feminidad y la masculinidad aparecen y desaparecen, se construyen y diluyen en el tiempo y el espacio histórico. La feminidad, a menudo considerada como símbolo de fertilidad y reproducción, abandonará los manifiestos de independencia para volver a expresarse a mediados del XX como "sexydad", volviendo así a una interpretación que viene de tiempo atrás y nos permite comprender el modelo androcéntrico característico de una tradición judeocristiana que marca fronteras asociando a las mujeres al cuerpo y la mera reproducción biológica de la vida. Por el contrario, el movimiento de mujeres que a comienzos del XX combatía por los derechos cívicos planteó una lucha por el reconocimiento, trató de ofrecer modelos alternativos que se expresaron en una representación como la "garçonne", y en general en las mujeres masculinizadas que iban "vestidas de hombres". Era el prototipo de la mujer no-sexy, de la amazona, de la confusión de sexos que recogen palabras de la época como "ginandria" o "andróginia" - otra cuestión es como las derivas de la moda han reciclado este modelo, construyendo, por ejemplo, hacia finales del XX, la androginia como sexy-.

La moda es una expresión estética que, junto con otras instituciones sociales, no está al margen de la ideología. Es coparticipe en la construcción del cuerpo y la identidad sexuada. Plagada de referencias a los sistemas simbólicos, ha diseñado una feminidad naturalizada y esencializada que remite a las mujeres a lo que considera como su naturaleza, pero también ha sabido recoger las reclamaciones políticas de los movimientos sociales más disruptivos cuando lanza el mensaje de que el sexo es una construcción cultural, máxime en ese periodo histórico de comienzos del XX en que hubo grandes diseños con nombres femeninos. Lejos, pues, de ser la manifestación social frívola que a veces se le supone, la moda refleja los contextos históricos y sociales de una determinada época, así como el estado de sus mentalidades, descubriendo las lógicas de los sistemas de representaciones. Además, la moda es quizás la demostración más clara de la sexuación social, la manifestación artística con más potencia para expresar la diferencia de sexos, pues sin su capacidad para remodelar los cuerpos, las fronteras y líneas rojas entre hombres y mujeres que la sociedad construye serían quizás menos nítidas, y por lo tanto, la confusión de sexos por lo que toca a la fisionomía corporal más frecuente. La moda tiende en principio a aprisionar el cuerpo de las mujeres con todo tipo de pseudoprotesis y corseterías, mientras que permite una gran libertad de movimientos en los hombres. Ahora bien, nunca estuvo más claro ni fue mas determinantemente puesto en cuestión este hecho diferencial que en las primeras décadas del siglo XX, cuando irrumpe todo un movimiento social de mujeres masculinizadas que recogen las consignas del movimiento sufragista y feminista. Las mujeres quieren votar, tener profesiones, optar a la custodia de sus hijos, etc. etc. Se trata de un movimiento que apunta hacia un tercer sexo o hacia formas unisexuales, en cualquier caso hacia un borramiento crítico de la diferencia

4 Citada en Roberts, M.L. (1990), Civilization without sexes. Reconstructing gender in postwar France, 19171927, Chicago: The University Chicago Press, p. 81. 
entre los sexos. A este movimiento se le puede dar el nombre de "garçonniere", pues la garçonne de formas masculinizadas es quien mejor lo representa. Es un movimiento que señala la ruptura con el corsé, tanto a nivel literal como a nivel metafórico, pues al tiempo que se introducen cambios en la vestimenta, la moda rompe también con muchos de los corsés mentales asentados en protocolos y costumbres sociales que sujetaban las mentalidades de las mujeres. La reforma social está en el aire, las propuestas de "amor libre" y "maternidad social", la otra cara de las críticas que se pronuncian hacia la esclavitud del matrimonio y el "amor encadenado", señalan que algo nuevo se estaba desatando en la joven generación.

Como es evidente, lo propio de la moda es no mantenerse impasible al paso del tiempo sino que, por el contrario, expresa el estado de las mentalidades de una sociedad determinada, reflejando sus formas de vida. El doble aspecto de expresión política y carga reivindicativa, que se le suele atribuir a la moda en nuestro momento histórico, se puso de manifiesto con la emergencia misma de las formas rudimentarias de la cultura de masas que aparecieron al despuntar el siglo XX. La expresión lingüística "abandono del corsé", un legado de esta época que aún se utiliza en nuestros días, responde, en su literalidad, como dijimos, a una nueva realidad estética para las mujeres. Pero es, por otro lado, una buena metáfora para expresar la cuestión política, pues lo ocurrido fue tanto una liberación del cuerpo y las formas vestimentales como el abandono de una visión mental limitada y estrecha. Por primera vez en la historia occidental conocida, el deporte, la playa, el cuerpo bronceado, la juventud y los "maillots" de baño se pusieron de moda -cuerpo y moda pasaron, de hecho, al primer plano de la escena social-. Un cuerpo móvil, dinámico y sin ataduras, se expresa en todo un movimiento social de mujeres independientes garçonnes, masculinizadas y "vestidas de hombres", mujeres que citan el estilo de los trajes y uniformes de las trabajadoras de las fábricas.

Ahora bien, con el auge del fascismo a mediados de los años treinta, con su apuesta por una masculinidad férrea, tradicional, violenta y militarizada, desaparece poco a poco lo que fue visto como el espíritu audaz de los "hombres de pelo largo" y las "mujeres de pelo corto". Los años que aproximan cada vez más la inminencia de la segunda guerra mundial son años de regresión, de vuelta atrás. Es una época en la que los ideales de la androginia y el acercamiento de sexos que se propugnaban en el feminismo y, en general, en los movimientos progresistas y pacifistas del período histórico anterior, se sustituyen por una vuelta a la tradición patriótica y nacional que dominó el siglo XIX. Según la historiadora Michelle Perrot, los tiempos de libertad "serán brutalmente detenidos o frenados por la crisis y la remontada de los totalitarismos resueltamente antifeministas" 5 . Tanto en la preguerra como en la guerra fría lo que se reconstruye es un estereotipo de feminidad que rompe con el modelo de independencia anterior. Se hace a través de los medios de comunicación, de la publicidad de las grandes empresas que son cada vez más claramente multinacionales como Coca-Cola y General Electric, empresas que dictan las reglas de la sociedad de consumo, y que necesitan de una mujer sexy y doméstica a la vez para vender sus productos. Es una feminidad mistificada ${ }^{6}$ que se diseña en los despachos de los nuevos ingenieros

5 Perrot, M. (2006), Mon Histoire des femmes. Paris: Éditions Point, p. 78

6 Cfr. el ya clásico estudio de la psicóloga social norteamericana Betty Friedan. Friedan, B. (1974), La mística de la feminidad. Madrid: Ediciones Júcar. También aborda el estudio de este mismo período histórico Preciado, B. (2010), Pornotopía. Arquitectura y sexualidad en $<<$ Playboy $>>$ durante la guerra fría. Barcelona: Anagrama. 
sociales, y que se recoge tanto en los aparatos de propaganda de los estados como en los medios de comunicación de masas. El cuerpo sexy de la pin up es un cuerpo que acentúa particularidades como el pecho opulento, las caderas anchas, la cintura estrecha, las piernas interminables y las nalgas generosas, es decir, una silueta femenina en forma de $\mathrm{S}$ que nombra a las mujeres en tanto que seres meramente sexuales y reproductivos. Como citando la feminidad victoriana, en sus dos versiones de la corista y la esposa puritana, las mujeres se sometieron de nuevo a los dictados de una moda que prescribía la exhibición provocativa del cuerpo femenino pero al tiempo lanzaba mensajes de domesticidad puritana, docilidad y sumisión. Desvirtuando lo que la garçonne había entendido por mujer nueva y emancipada, ahora la mujer moderna tiene que ser sexy -así se resignificaron negativamente las anteriores propuestas de liberación del amor libre-. La "sexydad" se convirtió en imperativo, e incluso en condición para la existencia, el ascenso y la promoción sociales. ${ }^{7}$

El movimiento de las mujeres masculinizadas, "vestidas de hombres", desaparece progresivamente en los años treinta, en paralelo con el auge del fascismo y la promoción de una masculinidad tradicional, violenta y militarizada. Los "hombres de pelo largo" y las "mujeres de pelo corto", que ya eran denostados en el periodo interbélico desde ideologías patrióticas y conservadoras como símbolo de un vuelco en las costumbres y un síntoma de un colapso del orden civilizatorio de Occidente basado en la hegemonía de una élite masculina, le cedió el espacio, en la preguerra y en la guerra fría, a las mujeres sexualizadas en el gesto, la mímica, la pose y el vestido. La pin-up es en gran parte todo un arte de la forma de sostener y mover el cuerpo. Como citando la feminidad victoriana, el cuerpo sexy de la pin up es el de una feminidad ideal de muñequita pícara e infantilizada en los bocetos de diseñadores y dibujantes. Y si bien la sufragista y novelista Harper Cooley, en su obra de 1904 "New Womanhood", había llamado la atención sobre el hecho de que la new Woman era aquella capaz de superar la posición over-sexed, la biopolítica de la sociedad del consumo, con sus aparatos de control de las poblaciones, su publicidad, sus potentes medios de comunicación de masas y su sistema de la moda inseparable de las chicas de la portada de las revistas femeninas, entierran la potencia crítica de las mujeres vestidas de hombres, vinculadas, por el contrario, a la emergencia de un movimiento feminista que en las dos primeras décadas del siglo XX alcanzó su punto de apogeo y radicalidad. La perdida de vigencia de afirmaciones como la que expresó la primera psiquiatra de Francia, la feminista Madeleine Pelletier, quien había asegurado: "Mi vestido le dice al hombre: soy tu igual" le cede el paso a una concepción de la feminidad que no es nueva sino que cita el viejo simbólico del eterno femenino, el que pone a la mujer del lado de la naturaleza y al hombre en el de la cultura.

De este modo, famosos dibujantes como Alberto Vargas y Gil Elvgreen, que trabajan para grandes firmas comerciales como Coca Cola o General Electric, rediseñan una feminidad corporal casi imposible, hipersexualizada y sexualmente sugerente. Los ilustradores de las revistas femeninas crean la feminidad ideal y la moda les sigue los pasos acentuando las cinturas de avispa y las caderas opulentas, recurriendo a la corsetería y las faldas tubo, las piernas interminables de los tacones de aguja, las melenas onduladas y brillantes como la de una pin up de referencia en el mundo cinematográfico: Marilyn Monroe, la rubia platino

7 Cfr Expósito, M. (2016) «El reino de las pin-ups», en: M. Expósito, De la Garçonne a la Pin Up. Mujeres y hombres en el siglo XX. Madrid: Cátedra, pp. 359-396. 
más explosiva. El movimiento de las mujeres había llevado la domesticidad a su crisis. Fue necesario que el "baby boom" y el retorno de las mujeres al espacio domestico se diseñase con procesos de ingeniería social, que se repitiese como una consigna en cada uno los gabinetes de sociólogos y psicólogos para poder así convencer a las mujeres de su vocación doméstica. El prototipo de cuerpo femenino que se pone de moda una vez llegados los años cuarenta hubiera quedado reducido a la nada sin el poder de los expertos, sin la capacidad de diseminación de los mensajes, sin la publicidad. Este tipo de cuerpo y de representación de la feminidad no es, por supuesto, un elemento insignificante a la hora de comprender nuestra historia cultural. Al ambicioso hombre de negocios que busca el triunfo empresarial que estipula el "make money" le corresponde una casa con piscina y una mujer en la urbanización suburbana, una esposa que haya pasado por la universidad y pueda interiorizar los mensajes simbólicos, rediseñándose a sí misma hasta convertirse en una consumidora profesional doméstica, en una especialista en higiene, dietas, cuidado de niños, etc., y que sobre todo comprenda cómo manejar los electrodomésticos que se presentan como objetos de deseo en los lemas publicitarios. El hogar tecnificado, el hogar como fábrica, se difunde en todo tipo de imágenes que tienen como complemento inseparable a esta nueva mística de la feminidad que acaba reconciliándose con la esfera doméstica y deja atrás a las mujeres profesionales e independientes que en una época anterior desmontaron los fraudes de la institución del matrimonio indisoluble, que no querían tener hijos y que desataron las agresivas campañas de las políticas natalistas. Todo empezó en los Estados Unidos... pero al final en los diversos países de occidente se trató de convencer a aquellas mujeres que empezaban a no diferenciarse mucho de los hombres de que su verdadera misión patriótica era la de proporcionar hijos al estado. Porque si la lengua marca el lugar de origen de las palabras, puede verse que el término francés "garçonne" sirvió para nombrar a la independiente europea mientras que la chica "pin up" delata su origen estadounidense.

En la pos primera guerra mundial se pensaba que las mujeres que aún seguían vistiendo el uniforme de trabajo ponían la raza en peligro -en realidad, la raza ya había sido diezmada por la caída de la natalidad en el mundo disipado de la belle epoque y por las innumerables muertes causadas por las batallas-. En esa época los despidos fueron masivos y las mujeres se encontraron en paro y sin recursos económicos, pero muchas se resistían o tenían ahorros y fueron sobreviviendo. El verdadero problema llegó en la generación siguiente, cuando los nuevos medios de comunicación de masas, en alianza con las grandes firmas comerciales y los sistemas de propaganda de los estados, van a plantear poco a poco la nueva forma de feminidad, aquella capaz de repoblar occidente aumentando el número de nacimientos. El proceso fue lento, tanto por la resistencia de las propias mujeres como porque se detuvo al llegar una segunda guerra que de nuevo le imprimió un giro a la historia de las mujeres porque se necesitó la mano de obra femenina. Ahora bien... fue "solo para la duración" del conflicto, como se dijo. Al finalizar la segunda contienda se había aprendido una lección sacada de la primera: que las mujeres podían resistirse a la domesticidad. Así que ahora la vuelta a la domesticidad se realizó con ayuda de los aparatos de propaganda y censura. Se promocionó de forma satisfactoria la feminidad sexy-doméstica que se consolidó en el periodo de la guerra fría. Sin embargo, la eficacia de las políticas de vuelta a casa supusieron el sacrificio de aquel derecho reclamado por el movimiento de las mujeres de las dos primeras décadas del siglo: el derecho a desarrollar una personalidad propia e independiente 
mediante la integración laboral y los derechos sexuales y reproductivos. Lo que triunfó fue la nueva feminidad diseñada por fabricantes de electrodomésticos y por la industria de la moda. Se impuso la pin up, la chica sexy digna de ocupar las hojas del calendario, de reproducirse en serie en todas las revistas, especialmente en las portadas de las masculinas como Play Boy.

El bikini es una de las prendas características de las pin up y en su momento provocó un gran escándalo. Se lanzó sugiriendo unos efectos devastadores, al igual que los provocados en el atolón del mismo nombre donde se hizo explotar la primera bomba atómica. El problema era que ninguna modelo aceptaba llevar el "tres piezas". De él se dijo que humillaba a la clase obrera pues su precio suponía el salario mensual de una dactilógrafa. Reard, su inventor, un ingeniero de automóviles, estableció una competición con su rival, un diseñador de trajes de baño llamado Heim que había diseñado un "átomo" que promocionaba como el traje de baño más pequeño del mundo. Al no encontrar una modelo que lo exhibiese, Reard tuvo que recurrir a una mujer que bailaba desnuda en el Casino de París. Al igual que las pin-ups, el bikini constituyó un hit, especialmente entre los hombres. La foto más vendida de la en ocasiones denominada como "reina de las pin-up", Betty Page, muestra, en una alegoría de la feminidad sometida, a esta modelo amordazada y atada en una red de cuerdas en la película "Leopard Bikini Bound". Considerado como la mejor invención del hombre, Reard intentó mantener la mística del bikini declarando que un dos piezas no era un auténtico bikini al menos que pudiera sacarse como un anillo de boda. Nueve años después, en 1955, la actriz francesa Brigitte Bardot promociona por primera vez en Europa el modelo de mujer-bomba cuando su primer marido, Roger Vadim, la filma en bikini para su película "Y Dios creó a la mujer", convirtiéndola así en la primera actriz que aparece en pantalla con esa prenda. Podría figurar como la lectura europea de la star Marilyn -aunque ella, al igual que la italiana Claudia Cardinale, sugieren también el lado del sexo salvaje de la jovencita lolita indomable, con un residuo fatal que parece, sin embargo, ausente en la simplemente sexy, inofensiva, pasiva y dulce, Marilyn Monroe-. Así pues, las mujeres de la mística de la feminidad desarrollaron formas corporales por medio de vestidos capaces de expresar la sumisión al hombre. Lo hicieron de buen grado, de forma complaciente, o como la única manera para sobrevivir en una sociedad androcéntrica que no había sido diseñada por ni para ellas, porque como rezaban los lemas de la publicidad... a ellas había que enseñarles que el mundo del "make money" era "un mundo de hombres". Los profundamente racistas y masculinistas años cuarenta y cincuenta negaron la mixtidad social y profundizaron así en la sexuación del mundo.

Simone de Beauvoir distinguía entre el mito del eterno femenino y las mujeres. No se trata de que el mito del eterno femenino se obtenga a partir de determinados comportamientos femeninos más o menos "naturales" sino que, por el contrario, el mito ha de construirse en las expresiones de la feminidad, en las representaciones del cuerpo que se ponen a disposición de las mujeres. ${ }^{8}$ La producción social e histórica de la feminidad es una cosa y la gran diversidad de las mujeres otra bien diferente. La garçonne independiente es una expresión estética de los ideales sufragistas y feministas, la sumisa pin up es una cita de la

8 Cfr. Beauvoir, S. (1976), Le Deuxième Sexe I Paris: Gallimard, y Beauvoir, S. (1962), Brigitte Bardot and the Lolita syndrome, Londres: New English Library Ltd. 
feminidad de los medios de comunicación de masas. Y la imaginería sexual masculina acerca de lo femenino de mediados del siglo XX fue producida mayoritariamente por hombres y para hombres; con nuevos cauces de expresión de la feminidad que, sin embargo, se acercan a los planteamientos antifeministas y estereotipados de siglos anteriores. Al efectuarse la ruptura con el movimiento social feminista y sufragista aparece un control de las mujeres en el espacio doméstico, un aparato de control que vigilaba e intervenía en el espacio de la representación. Se establecía lo que debe mostrarse de las mujeres y se censuraba lo que debe callarse. Incluso la posterior experiencia relatada por muchas mujeres de la etapa siguiente, los años sesenta y sesenta, nos recuerda que una cruel contradicción regía las relaciones entre hombres y mujeres dentro de la izquierda, pues si bien ellos subscribían valores emancipatorios y progresistas en el terreno ideológico, en la realidad concreta los valores de la mística de la feminidad seguían operando - mientras tanto, los feministas se ignoraban y se ridiculizaban-.

\section{Bibliografía}

Beauvoir, Simone (1976): Le Deuxième Sexe I, Gallimard, Paris.

Beauvoir, Simone (1962): Brigitte Bardot and the Lolita syndrome, New English Library Ltd, Londres.

Expósito, Mercedes (2016): De la Garçonne a la Pin Up. Mujeres y hombres en el siglo XX, Cátedra, Madrid.

Friedan, Betty (1974): La mística de la feminidad. Ediciones Júcar, Madrid. Perrot, Michelle (2006): Mon Histoire des femmes, Éditions Point, Paris.

Preciado, Beatriz (2010): Pornotopía. Arquitectura y sexualidad en $<<$ Playboy $>>$ durante la guerra fría, Anagrama, Barcelona.

Roberts, Marie Louise (1990): Civilization without sexes. Reconstructing gender in postwar France, 1917-1927, The University Chicago Press, Chicago. 